\title{
COMPRESSÃO MEDULAR POR METÁSTASE DE TUMOR DO MEDIASTINO
}

\author{
MARIA REOLON* \\ Ligia M. Barbosa Coutinho ** \\ JosÉ L. C. TEIXEIRA *** \\ CLÁudio G. ZetTLeR *
}

\begin{abstract}
O mediastino é sede freqüente de lesões neoplásicas e, das que se localizam em sua porção anterior, as mais comuns são representadas pelos timomas e teratomas.

O timo normal é formado por elementos epiteliais (corpúsculos de Hassal) e linfóides. Seus tumores podem originar-se em um desses tipos celulares ou em ambos ${ }^{11}$. Segundo Rubin 11, o termo "timoma" geralmente se refere aos tumores de origem epitelial, que são os mais freqüentes. Alguns autores chamam de timoma a todos os tumores originados no timo, incluindo neste grupo os teratomas. Schlumberger ${ }^{15}$ acredita que estes tumores tenham origem tímica, por deslocamento de tecidos durante a embriogênese. Os teratomas de mediastino são relativamente $\operatorname{raros}^{6,7,15}$. Rusby ${ }^{12}$, em 1944, coletou 251 casos da literatura. Durante a segunda guerra mundial, o Instituto de Patologia das Forças Armadas Norte-Americanas reuniu 29 casos, dos quais a terça parte era constituida por tumores malignos ${ }^{15}$.
\end{abstract}

Grande parte das neoplasias de mediastino são diagnosticadas ocasionalmente, em autópsia ou avaliação radiológica de rotina ${ }^{15}$. Lattes ${ }^{4}$, estudando 107 casos de tumores primitivos do timo, verificou que aproximadamente $40 \%$ deles eram assintomáticos, sendo que 11 constituiram achados de necrópsia e 32 foram visualizados em exames radiológicos de rotina.

Friedman ${ }^{2}$, em 1951, relatou um caso de teratoma de mediastino a que denominou germinoma. Caracterizava-se por apresentar células grandes, arredondadas, semelhantes às células embrionárias, com linfócitos dispersos no tecido, fazendo lembrar um tumor gonadal. Desde essa época outros casos foram relatados, nos quais a morfologia do tumor era parcial ou totalmente, semelhante a seminoma ${ }^{9}$. Estes tumores são raros, sendo considerados, às vezes, como metástase de um tumor testicular de difícil deteç̧ão ${ }^{1,6,7}$. Entretanto, os tumores gonadais primitivos raramente dão metástases para o me-

Trabalho realizado no Departamento de Patologia da Fundação Faculdade Católica de Medicina de Porto Alegre e apresentado no IX Congresso Brasileiro de Neurocirurgia (Rio de Janeiro, Julho-1972); * Residentes; * Auxiliar de Ensino; *** Residente do Instituto de Neurocirurgia de Porto Alegre, RS. 
diastino anterior ${ }^{10}$; habitualmente eles determinam comprometimento metastático em gânglios para-aórticos e retroperitoniais ${ }^{6}$. Até 1968 foram encontrados 38 casos de seminoma, considerados primitivos do mediastino.

\section{OBSERVAÇAO}

A.A.M., sexo masculino, branco, com 24 anos, em regular estado de nutrição, com queixa de dor no membro inferior direito há 6 meses. Há um mês apresentou paraplegia de instalação súbita, acompanhada de retenção urinária. Hospitalizado, o exame neurológico mostrou paraplegia sensitivo-motora com nivel sensitivo em D8. Os testes raquemanométricos realizados durante punção lombar, não modificaram a pressão liquórica. O exame do liquido cefalorraqueano mostrou 6 células/ $\mathrm{mm}^{3}, 470 \mathrm{mg} \%$ de proteinas, $79 \mathrm{mg} \%$ de glicose e $696,1 \mathrm{mg} \%$ de cloretos. Radiografia simples de coluna dorsal mostrou massa tumefaciente envolvendo o corpo vertebral de $D 8$, que se encontrava colapsado. A punção-biopsia vertebral não revelou alterações patológicas. A mielografia gasosa mostrou bloqueio total na altura da vértebra deformada. Foi indicada laminectomia dorsal. No início do ato cirúrgico, o paciente veio a falecer por parada cardiaca.

Exame necroscópico - No pulmão direito existia área de infarto hemorrágico, sub-pleural, de forma triangular, ocupando o segmento lateral basal do lobo inferior; os vasos desta região encontravam-se trombosados. Também o pulmão
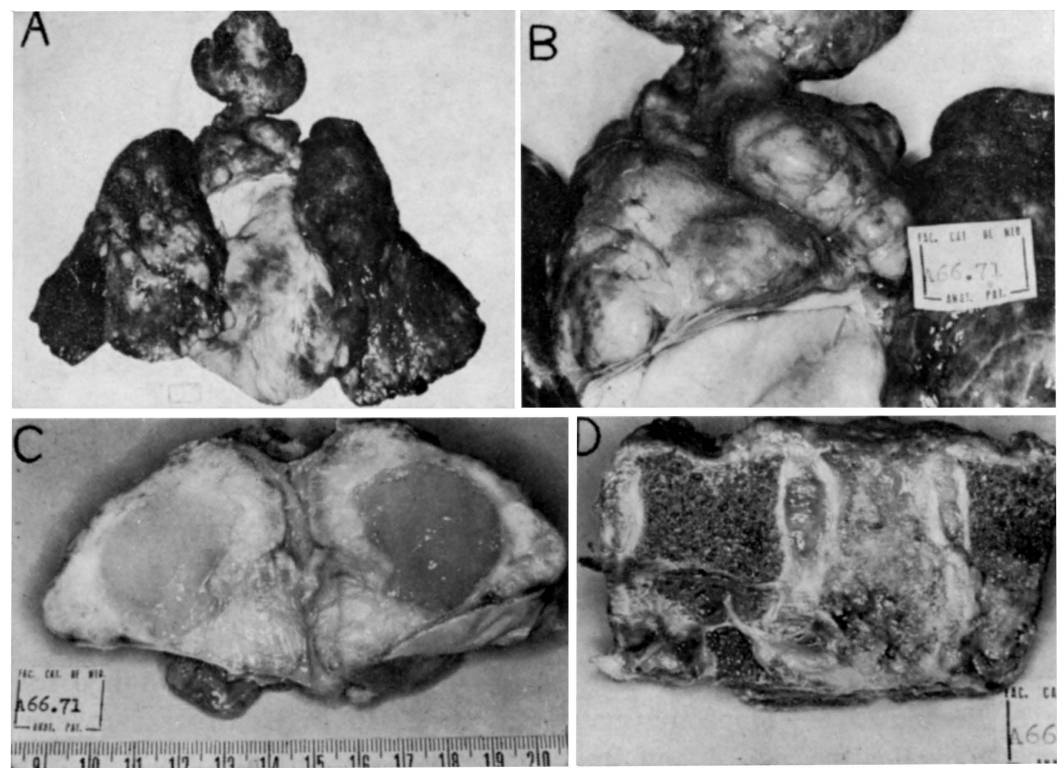

Fig. 1 - Caso A.A.M. Em A, peça de autópsia mostrando o tumor mediastinal multilobulado $e$ infartos hemorrágicos no segmento lateral basal do pulmão direito e no segmento superior do lobo inferior esquerdo; em $B$, detalhe do tumor mediastinal; em $C$, corte transversal do tumor, mostrando área cística; em $D$, corte longitudinal da 7.a, 8. ${ }^{a}$ e 9. ${ }^{a}$ vértebras, mostrando destruição do corpo de $D 8$. 
esquerdo apresentava área de infarto hemorrágico no segmento superior. Na regiāo correspondente ao timo observou-se massa bem delimitada, multilobulada, branca, fosca, medindo $6 \times 4 \times 2 \mathrm{~cm}$ e pesando $109 \mathrm{~g}$, frouxamente aderida aos tecidos vizinhos. Ao corte, apresentava-se lobulada, com área cística de $3 \mathrm{~cm}$ de diâmetro, contendo material gelatinoso cinzento. Fazendo parte dessa massa, identificavam-se alguns linfonodos que apresentavam, ao corte, superficie branca e fosca (Fig. 1). Após a retirada de todos os órgãos da cavidade torácica foi encontrada, ao nivel da 8.8 vértebra dorsal, massa com características semelhantes às da massa mediastinal, destruindo parcialmente o corpo vertebral (Fig. 1). Os demais órgãos não apresentavam alterações dignas de nota. Histologicamente, o tumor era constituido por células moderadamente grandes, arredondadas e poliédricas, de tamanho uniforme, com citoplasma levemente eosinofilico, núcleos grandes, vesiculosos e nucléolos proeminentes e ligeiramente eosinofilicos. As células se dispunham em grupos irregulares, circundados por septos fibrosos delicados, dando ao tumor aspecto lobular. Dispersas no tecido, encontram-se células linfóides e, em algumas áreas, células gigantes multinucleadas, semelhantes às células de Langhans. Vêem-se numerosas mitoses. O aspecto histopatológico é compativel com o diagnóstico de tumor seminomatoso (Fig. 2).
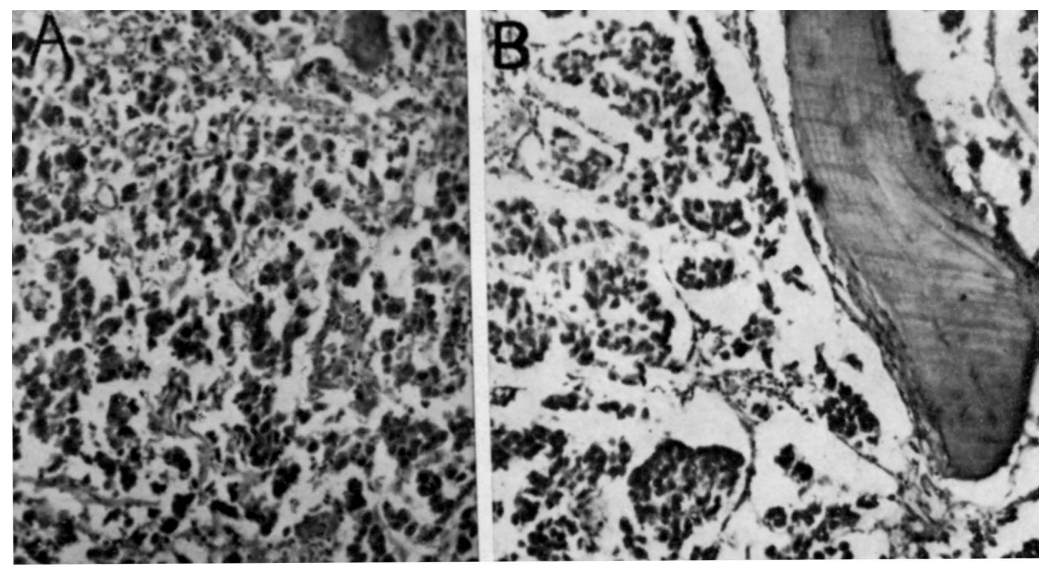

Fig. 2-Caso A.A.M. Em A, aspecto histológico do tumor, onde se observam células gigantes multinucleadas (H.E. $400 \times)$; em $B$, aspecto da metastase óssea (H.E. $400 \times)$.

\section{COMENTARIOS}

Os tumores do mediastino metastatizam inicialmente para os linfonodos regionais e pulmões ${ }^{15}$, podendo disseminar-se por via hemática, dando metástases à distância. O comprometimento metastático de estruturas ósseas por tumor de mediastino não é comum. Metástases de timoma para o crânio ${ }^{3}$, pelve ${ }^{16}$, femur ${ }^{14}$ e vértebras ${ }^{5,8,13}$ foram relatadas, bem como de teratomas malignos para vértebras ${ }^{15}$. No paciente cujo caso estudamos havia comprometimento metastático do corpo da $8 .^{a}$ vértebra torácica, determinando compressão medular, à semelhança de um caso relatado por Schlumberger ${ }^{15}$.

A localização primitiva de seminoma no mediastino é muito discutida, pois apenas uma cicatriz no testículo pode ser considarada como lesão primi- 
tiva ${ }^{1}$. Nos seminomas primários de mediastino relatados na literatura não foi observada lesão testicular em nenhum dos casos ${ }^{9}$. Para Oancea e col. ${ }^{7}$, a simples presença de um tumor em um homem jovem, a sua disposição topográfica no mediastino anterior, bem como a sensibilidade à radioterapia, seriam fatores importantes no diagnóstico de seminoma primário do mediastino.

O caso por nós relatado, por ser em um homem jovem, sem alterações morfológicas de testículo e por apresentar aspecto característico de seminoma, nos levou ao diagnóstico de tumor seminomatoso de mediastino, com metástase vertebral, determinando compressão medular.

\section{RESUMO}

relatado o caso de um paciente masculino, de 34 anos, com paraplegia de instalação súbita e nivel sensitivo em $\mathrm{D} 8$, cujo diagnóstico, realizado por ocasião da autópsia, foi de tumor seminomatoso de mediastino anterior, com metástase para o corpo vertebral de D8, determinando compressão medular.

\section{SUMMARY}

Spinal cord compression by metastasis of mediastinal tumor: a case report.

The case of a 24 year old male with crural paraplegia and sensitive level at $\mathrm{T} 8$ is reported. The thoracic spine films revealed an expansive process producing spinal cord compression and deformation of $\mathrm{T} 8$ vertebral body. A laminectomy was performed and the patient died by cardio-respiratory arrest during the surgery. The post-mortem examination discovered an anterior mediastinal tumor, the T8 vertebral body being involved by a mass with the same caracteristics. The hystopathologic study revealed a mediastinal seminoma like-tumor, metastasizing at $\mathrm{T} 8$ vertebral body.

\section{REFERENCIAS}

1. CASTElmaN, B. - Tumors of the Thymus Gland. In Atlas of Tumors Pathology, Section V, fascicle 19. Armed Forces Institute of Pathology, Washington DC, 1955.

2. FRIEDMAN, N. B. - Cit. por CASTELMAN 1 .

3. HASNER, E. \& WESTENGAARD, E. - Cit. por WHITAKER e col. ${ }^{16}$

4. LATTES, R. - Thymona and others tumors of the thymus. An analysis of 107 cases. Cancer 15:1224, 1962.

5. MINKowITZ, S.; SOLOMON, L. \& NICOSTRI, A. D. - Cytologically malignant thymona with distant metastasis. Cancer 21:426, 1968.

6. MOLINA, C.; MERCIER, R.; DelaGE, J.; LAGUILlaumie, B. de \& CHEMINOT, J. Cl. - Les seminomes du mediastin. Sem. Hôp. Paris 51:1416, 1965.

7. OANCEA, T.; ATANASESCU, S.; STEFANESCU-GALATI, Th.; POPESLU, P. \& SINGER, D. - Seminome mediastinal primitif. Sem. Hôp. Paris 44:580, 1968.

8. O'GARA, R. W.; HORN, R. C. Jr. \& ENTERLINE, H. T. — Cit. por WHITAKER e col. ${ }^{18}$ 
9. PATCHER, M. R. \& LATTES, R. - Germinal tumors of mediastinum: a clinicopathologic study of adult teratomas, teratocarcinomas, choriocarcinomas and seminomas. Dis. Chest 45:301, 1964.

10. PRUSTY, S.; BHAYANA, J. N.; NAYAK, N. C.; SINGH, S.; SINGHAL, V. S.; SHARMA, S. R. \& GOEL, P P. - Primary mediastinal choriocarcinoma. Dis. Chest 56:543, 1969 .

11. RUBIN, E. H. \& RUBIN, M. - Thoracic Diseases. Segunda edição. W. B. Saunders, Philadelphia, 1962.

12. RUSBY - Cit. por SCHLUMBERGER ${ }^{15}$.

13. SONADJEAN, J. V. \& SILVERSTEIN, M. H. - Cit. por WhITAKER e col. ${ }^{18}$.

14. SCALEY, J. R. \& COLLINS, J. - Thymona metastatic to bone: report of a case diagnosed by percutaneous biopsy. Radiology 96:423, 1970.

15. SCHLUMBERGER, H. G. - Tumors of the Mediastinum. In Atlas of Tumors Pathology. Armed Forces Institute of Pathology, Washington DC, 1955.

16. WHITAKER, J. A.; VOGLER, W. R. \& WERNER, J. H. - Red cell aplasia and osteoblastic metastasis in a patient with thymona. Cancer 26:427, 1970.

Departamento de Patologia - Fundação Faculdade Católica de Medicina Rua Sarmento Leite 245 - 90000 Porto Alegre, RS - Brasil. 